\title{
CULTURE UNDER THREAT
}

\author{
MINORITY HYPERLOCAL CABLE \\ TELEVISION IN FINLAND
}

\author{
Darren P. Ingram \\ University of Oulu \\ Pentti Kaiteran Katu 1 \\ 90014 Oulu \\ Finland \\ darren@ingram.fi
}

\begin{abstract}
Hyperlocal community television is currently under threat and its content documenting local memories and histories is underused and hardly accessible. Newly generated hyperlocal content runs the risk of not being archived, curated and preserved. Can new technologies that encourage hyperlocal media contribute to its demise? This article discusses the history of hyperlocal community television in Finland, considers its current challenges and draws awareness to the need of securing this local heritage for the future. The article debates how the future fate of this form of hyperlocal television is dependent on material resources, such as manpower, access to storage and preservation infrastructures as well as funding.
\end{abstract}

Keywords: local television, community television, minority language, disappearing archive, cultural archive, cultural heritage

A visit to a small general store just before Christmas, a municipal council meeting, or a cultural event may not appear to be important. Yet such events are recorded for posterity by a group of enthusiastic amateurs, usually without a background in broadcasting or creative arts, wishing to report on and document life in a small town or municipality. They are transmitted on a local cable television network serving as a hyperlocal television channel, operating perhaps for an hour or two most weeks and reaching up to a few thousand households. This describes hyperlocal community television, or for some hyperlocal minority community television.

Hyperlocal community television is currently under threat, both regarding continued operations as well as the preservation and use of existing archives that represent decades of cultural memory and documentary evidence of hyperlocal community life. These community television channels are to be found in some municipalities in Finland, broadcasting in Swedish, an official language, used only by $5.4 \%$ of the population. ${ }^{1}$ More people today have a foreign language as their registered mother tongue than Swedish native speakers. ${ }^{2}$ Despite this, Finnish and Swedish are the country's two official languages, with English invariably the first unofficial language. 
D. P. Ingram, Culture Under Threat: Minority Hyperlocal Cable Television in Finland

Threats to hyperlocal community television come from many areas: a changing media consumption landscape, technological change, demographics, societal changes and no doubt other factors.

This article is built on a mixture of three qualitative interviews with active community television volunteers, as well as broader desk research. All known operational hyperlocal cable television channels were contacted and invited to participate in the research, but the invitation received no response. Despite its small sample size that does not allow for generalizable conclusions, the research presented in this article provides valuable insights into hyperlocal community television, the threats it undergoes and the actions that could possibly counteract these.

As the author of this article, I also consume community television media and believe that this content deserves being saved for posterity, even if existing operations as we know them today may not necessarily continue in their current form in the near future. Community television is a small but important way to learn about a new municipality when one first moves into the region, and it provides additional historical and cultural references in addition to its current day reporting.

\section{Hyperlocal Community Television}

Hyperlocal community television is effectively an unknown concept within municipalities with a majority of Finnish speakers. Swedish speaking minorities are predominantly clustered around the southern and western coasts of the country in a number of municipalities. Some of these municipalities can be small: my own municipality has a population of just over 5,200 people, and a population density of about 36 persons per square kilometre. It is also host to an active community television station who assisted with my research.

It is this clustering and a desire to access television broadcasts from Sweden - as a way to supplement or compensate for broadcasts from public service broadcaster YLE (the Finnish Broadcasting Company) - which inspired the creation of local cable distribution networks under circumstances in which most households could not receive over-the-air signals directly from Sweden. Through the creation of such cable redistribution television networks - the first being in Nykarleby in $1969^{3}$ - a few curious people saw the potential of making community television, which gradually become a reality.

The first community television TV transmission took place on November 22, $1972^{4}$ in the town of Jakobstad, followed a few weeks later by the premiere of another local TV service in the neighbouring town of Nykarleby, that featured excerpts from a 'Lucia' event at a youth centre, a speech from the town manager, and a religious devotion. After this, transmissions of community television were quite sporadic, but the phenomenon piqued the interest of citizens and other potential local television broadcasters in different Swedish-speaking areas of the country.

Community television came into focus and gained impact in the late 1980s, following some early interest in 1983 resembling its 'gold rush' period. A timeline of the development of community table is shown at the end of this article (figure 1). A couple of community television channels sought to establish themselves on commercial grounds, rather than the typical non-commercial mode of operations, yet without success. It can be considered that community television was too hyperlocal, underfunded and suffered from broader competition from other media actors and formats. 
Getting access to the cable television network was relatively easy, it was either owned by a co-operative or local telephone company. That said, limitations existed. Each channel was built on the goodwill of a few dozen people at best and had a very tight budget dependent on voluntary contributions from the audience, local sponsorship and other grants-in-aid.

In 1993 the Finland-Swedish Local TV Association (Förbundet Finlandssvensk Lokal-TV), was formed to help consolidate and develop activities among community television providers. It is worth noting that there has never been a comparable equivalent of community television in the Finnish-speaking majority area of Finland. Nor has there been any interest so far to provide community television in other languages. A 1987 Finnish law stipulates that capacity must be provided for community television on cable television networks, although it does not hold the operator responsible for the content creation of any form. It is merely a 'must carry' type of obligation.

\section{Programming for the Community}

The type of programming typically carried on community television does not pose a threat to mainstream broadcasters, nor is it likely to be something that ordinarily will generate a substantial income stream through syndication or re-use rights. Programming may include broadcasts from local council meetings, election debates, visits to local companies and organizations, events such as fishing and community meetings and so forth. Programmes are typically linked by a host. Transmissions usually occur once a week, with often a break for the summer holiday period (although this does not necessarily inhibit recording of material for future use).

In the past community television had to share channel space on many cable television networks, although upgrades to cable network infrastructure and also the move to IPTV meant that a dedicated channel location was possible. This gave the additional advantage of permanent branding, as well as the opportunity to sell advertising on a rotating banner. Consideration has been given to using this channel capacity to rebroadcast older material and timeshift more current transmissions, but resourcing and technological issues so far have impeded this. Similarly, there has not been a move to directly transmit over the internet to viewers, primarily on cost and technical grounds, but a few channels have begun to use video sharing sites to offer post-transmission access to individual programming elements.

What is popular programming for local television networks? This is a difficult question to answer as there is no explicit, reliable feedback mechanism. Some feedback may occur at a community level, with local television volunteers receiving or hearing comments about past programmes, or observing commentary on social media, but this has not helped provide exact data. Occasional programming that involves audience participation, such as quiz shows, may indicate the presence of audiences for this type of television. There are at most a few incoming telephone lines available for contact with audiences, which process a couple of dozen calls or even up to one hundred over the duration of a whole transmission or programme segment. This is hardly indicative of a vast audience out of a few thousand households, yet it does not necessarily substantiate low audience figures either.

One way to gain some indication of viewership - despite being unrepresentative on many levels - is by means of viewer counts on video sharing websites. In July 2019, for example, the most popular 10 videos on Larsmo När-TV's YouTube channel show viewer counts from 3,108 to 14,992. The YouTube channel was opened in late January 2017 and has amassed 372,933 views as of July 2019. These videos were, with the exception of one recent event (a 175-foot boat move that got even international attention) more 'nostalgic' and clearly local in nature, such as a 1992 song 'Dream of my Larsmo' (see video 1), a 1990 production featuring moped-riding youngsters (see video 2) and a 1989 feature about a popular small store's preparations before Christmas (see video 3). Another active community television channel Malax TV has focussed more on its own website with an integrated video player linking to Vimeo. It is not possible to identify individual programmes that were in demand as uploads were made on a 'per evening' basis. The top 10 videos attracted between 1399 and 5066 views as of July 2019. 


\section{VIEW}

D. P. Ingram, Culture Under Threat: Minority Hyperlocal Cable Television in Finland

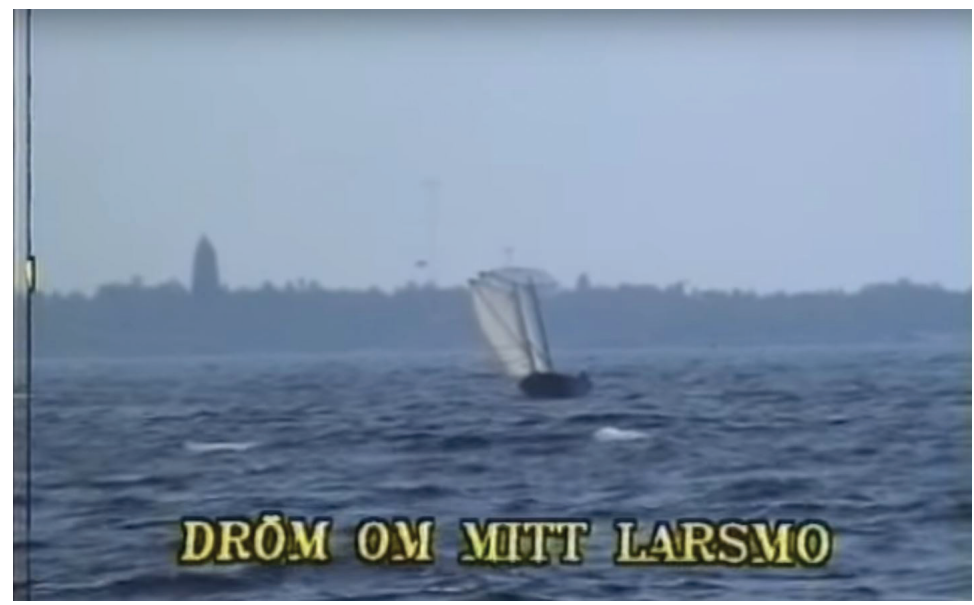

Video 1. Dream of my Larsmo, Larsmo När-TV 1992.

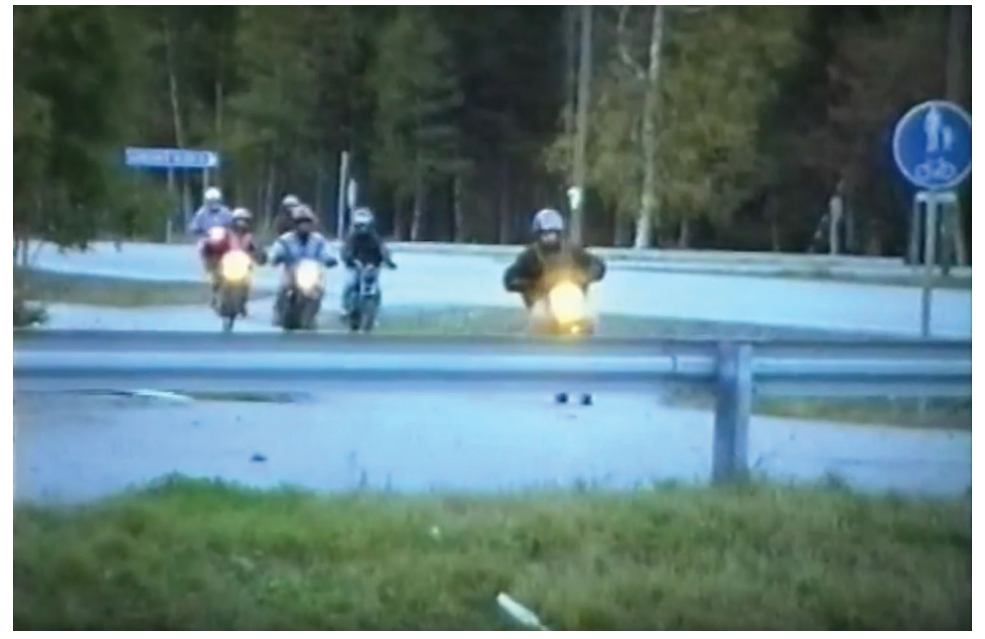

Video 2. A 1990 production showing youngsters riding mopeds, Larsmo När-TV.

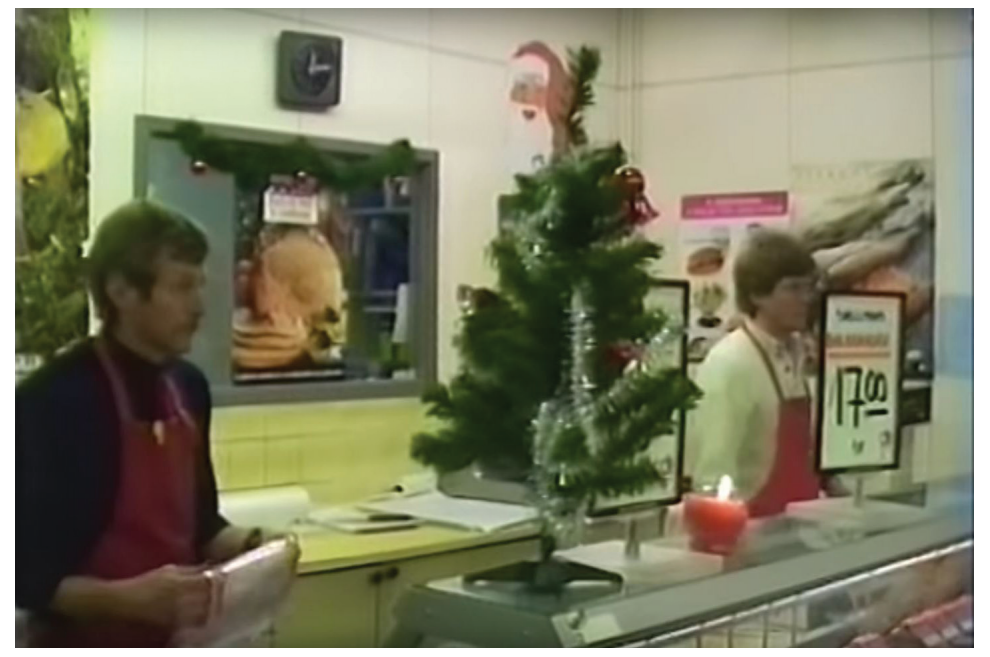

Video 3. A 1989 production showing a small store's preparations for Christmas, Larsmo När-TV. 
Potential audiences for these community television channels are not significant in themselves, as they are limited to the reach of few thousands households of the cable network and compete with other programming for viewer attention. Even on a national level, television viewing is rather fragmented: beyond the dominant channels of YLE TV1 (28.1\%), MTV3 (16.3\%), YLE TV2 (12.4\%) and Nelonen (9.6\%), the other channels have ratings below $4 \% .{ }^{5}$ Suddenly, for a specialist channel, getting even an estimated $10-40 \%$ of household share ${ }^{6}$ for a live broadcast can be positive, without even considering any 'catch-up', video-recorded or on-demand access. This data is further substantiated by some community television operators, who have reported the average contribution by municipality members of a voluntary nominal payment, which in my local channel's case is $12 €$ per year, this being in the $30-40 \%$ range of households.

Beyond issues of audience shares, it seems that community television endeavours raise a broader awareness at least, even if people do not or cannot watch it. One concrete example of someone not being able to watch local community television channels at home, but who would like to, is myself. As a family, we do not subscribe to cable television, so the only access we get is to videos uploaded to YouTube or when visiting my mother-in-law during the times that broadcasts take place.

\section{Nothing Stands Still}

At the start, the technology needed to record, edit and transmit community television was still under development and expensive. There was no out of the box solution, nor was there an outsourced service to use, and even if this was available, there would not have been the funds available to spend on it. Instead, groups of enthusiastic and self-taught amateurs would experiment with generating a couple of hours of programming per week, using the equipment they could acquire with limited resources. Local community television stations have also had to face technological developments that cut through the entire TV industry, such as migration from analogue to digital production technologies. The underlying cable television networks, where the community television channels are relayed, also had a similar technology shift to deal with.

For viewers, additional programming choice came with direct-to-home satellite television, but on the whole, this was a temporary distraction or interest for most. The next shift, involving Internet Protocol Television (IPTV), has been more nuanced and primarily impacted the network operator, although it has the potential to help make community television channels visible on other (non-local) cable television networks. This is already happening, although it is mostly evident on cable television networks that are operated by a company covering several municipalities and community television operations. Some cable network operators offer an additional 'mobile TV' service to their cable television subscribers, utilising the same IPTV service which is accessible over the internet for mobile devices. However, the programming selection is scarcer and does not feature (at least on a dominant provider platform) access to community television channels.

Greater consideration needs to be placed on the distribution of community television going forward, but the question of who will pay for this remains. Many, particularly the younger demographic, watch video content mostly through online services such as YouTube, eschewing entirely traditional over-the-air, cable and programmed video services. This adds further threats to community television services, in terms of potential viewership and even possible voluntary support. In the past, tech-savvy people would become involved with the technology and make community television. Today, the impetus to become involved in a community project is lesser in a context in which everyone armed with a smartphone, a data plan and a few apps or websites can be a broadcaster in their own right at a low cost, using a (smartphone) camera that can outperform a 1980s or 1990s-era video camera.

5 Statista, 'Leading television channels in Finland in 2017, by audience share,' 25 April 2018, https://www.statista.com/statistics/633922/ tv-channels-in-finland-by-audience-share/

6 This is based on my own and other community television networks estimates. 
The fact that the viewers increasingly eschew live programming according to a pre-set schedule is a given in the broader broadcasting world. This is no different for community television, even if viewers in principle wish to follow such programming out of local interest. That is why community television should switch to online transmission, whether live streaming or on-demand video, which would be desirable even though it creates more work for an already over-stretched, under-manned core of volunteers.

One attempt at diversification has been Malax TV's attempt at pay TV, whereby a couple of programmes featuring a local ice hockey league have been placed online password-protected and made accesible at the cost of $2 € / 20$ SEK paid via SMS. This has been an experiment so far, and unlikely to be a great source of income in itself.

On top of struggling to make programmes, there are other challenges facing community television, such as the preservation of their archives, considering and providing online video access, maintaining a broadcast environment, and organizational matters such as running a 'company' that is in fact an association. Considering that one minute of video worth of watching takes more than one minute of time and resources, the scarcity of resources to sustain all these activities is glaring.

\section{Gradual Decline}

Maybe the end is nigh for community television as we know it. Whether that is the case or not, what has been produced so far should be preserved. At the same time what may be generated in the future - in whatever format that might represent community television or the audio-visual documentation of a local society - should also be ideally curated, indexed and preserved as part of cultural heritage.

It seems clear that some community television channels appear to be running out of steam, judging by their online presences (or the lack thereof) and their lack of response when contacted. It is also clear that some channels are trying to remain active and relevant. Interviewees admit that they can be fighting against the inevitable future, but it does not mean that they are defeatist or willingly giving up. Such operations have never been over-flooded with money and resources, and these two issues have been identified as areas of concern in the past couple of decades by the Finland-Swedish Local TV Association. Inevitably, when these two resources have shrunk, often in tandem, to dangerous levels or worse, another community television station comes to an end and closes.

Attempts are being made to attract younger volunteers and make programming accessible to a broader audience. Experiences with younger members who have been drawn to community television over recent years have been mixed, with most dropping out when they discover the complexity of the tasks involved and the specific, disciplined approach that is required. Exceptions exist, of course, but they are notable by being exceptions. With an ageing group of volunteers, it is understandable that they cannot be so active as time goes on, and without sufficient resources available, things may unfortunately grind to a halt. Attracting new volunteers is no easy feat, and the number of active volunteers is on the decline.

This is not a matter of changing to the model of a 'big business' either, and the actual financial sums involved are rather small when put in perspective. One community television channel (who may be considered as well-off) admitted to having a yearly budget of about $60,000 €$, obtained through grants, voluntary contributions, limited on-screen advertising sales, and occasional external service provision. Trying to secure income, however, is difficult - whether by means of donations-in-waiting or payment for services rendered - and it demands even more time and resources that are not available in a context of existing scarcity. Approximately half of resources are spent on a full-time employee who coordinates and manages many core activities. The costs for studio space, production and occasional equipment purchase are charged to whatever funds remain. It has become a luxury to get a programme recorded and on-air at the cost of a few cups of coffee as fuel for the volunteer programme staff. 
The Finnish-Swedish Local TV Association acknowledges the situation and desires to revitalize and reenergize community television. A business model had been proposed to replace some of the voluntary operations of these enterprises with an employed workforce, using a modest revenue stream. The intention is not to make profit, but to sustain operations for the future. This is a paradoxical situation, raising questions about who pays and who can raise funds to help pay for people to get funding and resources to drive future operations.

\section{Risk of Cultural Loss}

The hyperlocal content of community television is spread out, transient and invariably not fully and externally archived. A lot of local cultural memory and history is at risk of being lost. It is not even a case of struggling to determine what should be archived, conserved and retained. There is currently no standard/formal process or infrastructure in place to support any archiving or preservation activities.

Who will produce, document, curate and archive hyperlocal content in the future? That is a good question with unfortunately no concrete answers. Making content will continue in various forms, even if community television channels stop their operations. This will not be done in an organized manner, and it may not be distributed outside a core group of friends and family, such as most social media postings today demonstrate. Even if such material is uploaded to a video-sharing site, access to the content is dependent on searching for the right keywords and, of course, it requires the video-sharing site to remain online. History shows us that once popular internet websites can suddenly close and their content is under threat unless salvaged by entities such as the Internet Archive.

Knowing what is in the existing community television archives can be a challenge, especially for viewers and researchers (and maybe even for the channel itself at times). Adding video material to websites and video sharing services can help, assuming sufficient metadata is provided, but all of this demands resources. Only one community television operator has, it seems, sought to make a list of its (known) archive material publicly available, through a Google Docs spreadsheet. With this, researchers and other interested parties are explicitly invited to identify content of interest and order it on DVD. No mention of the cost is stated, although any costs are likely to be considerably less than those charged by commercial archives and institutions.

Based on discussions with some of the more active community television networks that remain operational, it may be a conservative estimate to suggest that around ten thousand hours of the total programming have been created and archived in theory. This is a low figure by commercial television standards but it is still a valuable source of community heritage documenting local histories and memories.

A very large proportion of local television programming remains locked away and out of reach even for purposes of reuse or easy access. The material is stored on video cassettes (mainly VHS), and some material is stored on DVD. Some local television channels are seeking to transfer this material at least to M-Disc for its alleged superior archiving longevity. Format degradation and eventual playback issues are present, as well as access and delivery problems in the event of content reuse. Even if new material can be originally recorded on digital formats, and certainly edited within a digital workflow before being primed for transmission through different architectures (budgets do not necessarily provide for a complete digital playout system just yet), some of the production equipment may still require digital transfer or import/conversion. Video sharing sites such as YouTube and Vimeo are also being used as online, additional archives.

Even if the digitalization backlog can be resolved, it is not necessarily easy to make the material available online for future consumption due to issues regarding licensing. Community television networks have compliant licensing with the Kopiosto copyright society, and they also need to consider the rights of composers and music publishers through the Teosto not-for-profit administration agency. Different agreements cover traditional television programming and online distribution, and this can create issues and costs, especially for certain types of programming such as music 
concerts and theatrical performances, or even other programming that may have used music in the background or within links. Archival usage was never a prime consideration and thus detailed logs of content metadata for relicensing or reporting, even if economically practical, may not exist. Put bluntly, there is no imperative to invest time and resources on the task, should licensing issues be present, and indeed this can impact the decision to upload/transmit an old programme that has musical works such as a concert or theatre performance as its prime focus. Peripheral material, perhaps with some background music, may be less risky, if not licence-free.

\section{What Needs to be Done?}

If the eventual demise of community television is accepted, something needs to be done to preserve its content and cultural memory for the future. Equally, the informal, but substantial, relevant content that is being produced today and shared on social media and the internet-at-large should be archived. Who will do this, and who will pay for it, is the bigger question.

Clearly, it can be argued that it is of national interest. Involving local actors such as a library or archive with supporting funding is a possibility. Existing library and archive infrastructures could be used to aid the process of preservation and provide a platform for accessibility and content exploration in the future. Some elements may need a vision and a community drive. Other elements may just need a refocusing and redistribution of existing resources. A group of archivists could seek to harmonize and unify other elements such as image fidelity, storage formats, metadata and transfer techniques, ensuring that best practices are followed where possible.

Preservation must be seen as essential for the active community television stations. This should be an immediate action, with content deposit and retention being necessary. Support, whether physical or financial, to digitalise content holdings from analogue tapes is a key priority too. A process to store online copies of material on DVD or M-Disc can run simultaneously.

Research should be carried out to identify what has happened to the output of inactive community television networks, attempting to retrieve it when possible. Consideration should be given to saving the material artefacts of this institutional and cultural form of television, such as documentation from the community television networks, flyers, mementos, analogue programme carriers and so forth.

Whatever is developed can be used as a similar funnel for content that is generated today and stored already in a digital format.

Even as a stop-gap measure, some public funding to secure archival cloud storage, such as an Amazon or Google product, would help provide an additional storage solution, while a longer-term, more integrated solution is found. A lot of the material would be in standard definition format, unless its fidelity has already been reduced by storage on DVD. Even a rough calculation of 10,000 hours of video - assuming that each hour that filled a DVD $(4.7 \mathrm{~Gb})$ would be $47 \mathrm{~Tb}$ with no retrieval usage - would be in the range of at least $250-350 €$ per month. This cost could decrease substantially if accounted for by an institution with its own storage infrastructure or outsourced agreement. As various initiatives exist, both on a national and European level, for providing archival access to history, memory and other heritage content, this should not be viewed as an impossible flight of fancy either.

Undoubtedly much more could be done, but this all comes at the cost of time, materials and manpower and this understandably can be beyond the reach of these community associations with insufficient budgets. So far there does not appear to be any coordinated intention by libraries and other concerned bodies in Finland to offer assistance, whether custodial, conservational or financial, for this small, but relevant historical and cultural archive. In some localised cases copies of material, such as converted or duplicated media, may be deposited at the municipal level in a local library or local studies association, but these are ad hoc arrangements at best. 
D. P. Ingram, Culture Under Threat: Minority Hyperlocal Cable Television in Finland

\begin{tabular}{|c|c|c|c|}
\hline Location & Association/Company & Launch Year & Current Status or Date Ceased \\
\hline Vasa & Anvia (Wastel) & 1984 & INACTIVE (believed inactive/no online trace of current operations) \\
\hline Pedersöre & Bonde-Bur CA & 1986 & stopped in 1990 \\
\hline Dalsbruk & Bruks-TV & 1987 & 1999 \\
\hline Munsala & Bygde-TV i Munsala & 1988 & 2003 \\
\hline Åbo & BY-TV/KYLÄ-TV & 1984 & 1987 \\
\hline Ekenäs & Ekenäs TV Ab & 1984 & ACTIVE (merged in 2014 with KEXTV) \\
\hline Forsby & Forsby Lokal-TV & 1986 & 1987 \\
\hline Jakobstad & Jakobstad TV Pietarsaari & 1972 & ACTIVE (active in current form from 1989) \\
\hline Karis & KEXTV/Karis TV Ab & 1989 & ACTIVE \\
\hline Kaskö & Kasvisionen Ab & 1984 & $\begin{array}{l}2012 \text { (believed inactive/merged with Anvia network/previously } \\
\text { transmitted municipal information) }\end{array}$ \\
\hline Malax & Klockarbackens TV & 1983 & Merged \\
\hline Karleby & Kokkola TV Oy & 1987 & 1999 \\
\hline Kristinestad & KRS-TV & 1980 & ACTIVE \\
\hline Korsnäs & Kust-TV r.f. & 1984 & 1987 \\
\hline Pedersöre & Kållby Lokal-TV & 1982 & 2010 \\
\hline Vörå-Maxmo & Kärlax Lokal-TV & 1989 & 1989 (previous co-operation with Maxmo-Tottesund Lokal-TV) \\
\hline Pedersöre & Lappförs När-TV & 1988 & 1991 \\
\hline Larsmo & Larsmo När-TV r.f. & 1988 & ACTIVE \\
\hline Malax & Malax TV Produktion & 1980 & ACTIVE \\
\hline Maxmo & Maxmo-Tottersund TV & 1988 & 1998 \\
\hline Nykarleby & NY-TV & 1972 & ACTIVE (appears to only send municipal information ) \\
\hline Närpes & Närpes När-TV r.f. & 1982 & ACTIVE \\
\hline Pargas & Pargas När-TV förening r.f. & 1987 & INACTIVE (believed inactive/no online trace of current operations) \\
\hline Pedersöre & Pedersöre TV & 1987 & $2013 ?$ (believed inactive/no online trace of current operations) \\
\hline Malax & Petalax-TV & 1982 & ACTIVE \\
\hline Korpo-Nagu & Skärgårdskanalen & 1989 & Inactive (believed inactive/no online trace of current operations) \\
\hline Solf & Solk Lokal-TV & 1993 & ACTIVE (co-operation with Malax TV \\
\hline Sundom & Sundom TV & 1984 & ACTIVE \\
\hline Åland & TV Åland & 1984 & ACTIVE (private TV, various owners over time) \\
\hline Vörå & Tålamods TV & 1989 & 1989 \\
\hline Vanda & Wanda Videonet & 1988 & INACTIVE \\
\hline Terjärv & Vi i Terjärv r.f. & 1981 & $1983 ?$ (believed inactive/no online trace of current operations) \\
\hline Hangö & $\begin{array}{l}\text { Video } 27 \text { (Hangö Lokal-TV } \\
\text { förening r.f.) }\end{array}$ & 1989 & INACTIVE (believed inactive/no online trace of current operations) \\
\hline Vörå & Wör-TV & 1989 & ACTIVE \\
\hline Malax & Yttermalax Lokal-TV & 1985 & Merged (merged with Malax-TV 1986) \\
\hline Yttermark & Yttermark Gillet r.f. & 1986 & ? (believed inactive/no online trace of current operations) \\
\hline Oravais & Årvas TV & 1989 & ACTIVE \\
\hline Malx & Övermalax Lokal-TV & 1983 & Merged (merged with Malax-TV) \\
\hline Borgå & TV-Borgå & 2001 & INACTIVE (believed inactive/no online trace of current operations) \\
\hline
\end{tabular}


D. P. Ingram, Culture Under Threat: Minority Hyperlocal Cable Television in Finland

\section{Bi o graph y}

Darren P. Ingram is a doctoral researcher at the University of Oulu in Finland. Following decades of journalism, media and business experience, he switched to academia later in life. His research interests lie within the media, language, business and technology worlds, primarily where they can interact and interconnect. More information can be found at Darrenlngram.com. 